\title{
Home-based management of knee osteoarthritis during COVID-19 pandemic: literature review and evidence-based recommendations
}

\author{
Theofilos Karasavvidis ${ }^{1}$, Michael T. Hirschmann ${ }^{2}$, Nanne P. Kort ${ }^{3}$, loannis Terzidis ${ }^{4}$ and Trifon Totlis $^{1,4^{*}}$ (D)
}

\begin{abstract}
Purpose: To provide evidence-based recommendations for patients with severe knee osteoarthritis (OA), who had their knee surgery postponed due to the COVID-19 pandemic.

Methods: PubMed/Medline, Scopus and Cochrane Central databases were systematically reviewed for studies reporting outcomes of home-based treatments for knee OA. Due to between-study differences in treatment strategy and reporting methods the results were not pooled and findings of the current review were presented in a narrative manner.

Results: The comprehensive literature search yielded 33 eligible studies that were included in this review. Management is performed at home and consists of exercise, proper nutrition, physical therapy and use of corrective and assistive orthotics. Virtual education on self-management strategies should be part of coping with knee OA. Initiating an exercise programme involving gymnastics, stretching, home cycling and muscle strengthening is highly recommended. Obese patients are encouraged to set weight loss goals and adopt a healthy diet. Potential benefits but weak evidence has been shown for the use of knee braces, sleeves, foot orthotics or cushioned footwear. Walking aids may be prescribed, when considered necessary, along with the provision of instructions for their use.

Conclusion: When bridging the time to rescheduled surgery, it is essential to use appropriate home-based tools for the management of knee OA if pain is to be reduced and need for analgesics or opioid use is to be diminished while maintaining or even improving the functioning and avoiding further limitation of range of motion and subsequent muscular atrophies. Finally, none of these treatments may completely substitute for the life-changing effect of a total knee arthroplasty in patients with severe knee OA. Hence, the subsequent goal is to gradually and safely reinstate elective surgery.
\end{abstract}

Keywords: Osteoarthritis, Knee, COVID-19, Home-based, Exercise, Diet, Physical therapy, Corrective devices, Total knee arthroplasty

\footnotetext{
*Correspondence: totlis@auth.gr

'School of Medicine, Faculty of Health Sciences, Aristotle University of

Thessaloniki, University Campus, 54124 Thessaloniki, Greece

${ }^{4}$ Thessaloniki Minimally Invasive Surgery Orthopaedic Center, St. Luke's

Hospital, 55236 Panorama, Greece

Full list of author information is available at the end of the article
}

\section{Springer Open}

(c) The Author(s). 2020 Open Access This article is licensed under a Creative Commons Attribution 4.0 International License, which permits use, sharing, adaptation, distribution and reproduction in any medium or format, as long as you give appropriate credit to the original author(s) and the source, provide a link to the Creative Commons licence, and indicate if changes were made. The images or other third party material in this article are included in the article's Creative Commons licence, unless indicated otherwise in a credit line to the material. If material is not included in the article's Creative Commons licence and your intended use is not permitted by statutory regulation or exceeds the permitted use, you will need to obtain permission directly from the copyright holder. To view a copy of this licence, visit http://creativecommons.org/licenses/by/4.0/. 


\section{Introduction}

Osteoarthritis (OA) is considered the most common type of arthritis and the most prevalent joint disease in adults [1]. Total knee arthroplasty (TKA) has been proven to be an exceptional and dependable treatment for end stage knee OA, with satisfactory clinical outcomes up to 20-year follow-up [2]. The beneficial influence of knee arthroplasty on symptom management, social life, patient satisfaction and overall health promotion is indisputable [3].

Coronavirus disease 2019 (COVID-19) has evolved as a pandemic throughout the world; it constitutes an unprecedented challenge for the personal and professional lives of healthcare providers and has severe socioeconomic consequences for most countries [4]. During these efforts to delay the spread of the virus and protect patients and staff, hospitals have had to stop most nonCOVID-related activity and postpone the majority of elective surgeries, including knee arthroplasties [5-7]. Notably, the COVID-19 survey of European Knee Associates (EKA) and European Hip Society (EHS) members in April 2020 demonstrated that $92.6 \%$ of surgeons had stopped total joint arthroplasties, while the American Association of Hip and Knee Surgeons (AAHKS) COVID-19 survey showed similar data in the USA, where $92 \%$ of hospitals had stopped elective surgeries [8, 9]. Likewise, Asian orthopedic surgeons had postponed all surgeries requiring $>23 \mathrm{~h}$ of hospitalization [10]. In addition, knee surgery could increase the risk of complications for ageing patients [4] given that they are at increased risk of severe COVID-19. However, delaying elective TKA in patients with severe OA may lead to increasing joint pain, less mobility, functional limitations and increased use of analgesic and opioids. More recently, most countries have begun to consider a restart of elective surgeries, including knee arthroplasties [11, 12]. However, the safety of patients and medical staff remains crucial and as such, the gradual reinstatement of elective joint replacements will be an ongoing and timeconsuming challenge [13].

The aim of the present review is to provide a guideline for physicians to lead the patients with knee OA, who had their knee surgery postponed due to COVID-19, through their home-based treatment. Even though current sanitary measures such as social distancing seem to contribute to a flattening of the curve, they constitute burdens for patients suffering from severe knee OA, who often cannot come into direct personal contact with their physician or physical therapist responsible for medication prescription or physical therapy sessions respectively. It is against this background that this review focuses on available home-based non-pharmacological options with the goal of mitigating pain, improving function and preventing further progression of the disease.

\section{Methods}

\section{Study selection and data extraction}

Systematic searches were conducted in PubMed/Medline, Scopus and Cochrane Central according to the Preferred Reporting Items for Systematic Reviews and Meta-Analyses (PRISMA) guidelines [14]. The databases were reviewed using the following search terms in several combinations: "home-based", "exercise", "physical activity", "training", "strengthening", "aerobic", "blood flow restriction", "BFR”, "diet”, "weight loss", "nutrition”, "physical therapy", "brace”, "orthotics”, "footwear", "walking aids", "cane", "walker", "osteoarthritis" and "knee”. All publications up to 26 May 2020 were searched. Two authors, independently and blind to each other, screened the titles and abstracts of all the articles identified. If the abstract was unavailable, the paper was excluded. In the event of disagreement, a consensus was reached by discussion, if needed with the intervention of the senior author. Randomized controlled trials (RCTs), prospective or retrospective analyses as well as systematic reviews and metaanalyses, reporting on conservative management of knee OA, were included in this review. A study was excluded from this review, if the treatment described was not possible to be performed at home.

Two investigators independently extracted the relevant data from eligible studies. All disagreements were resolved following discussion and the final decision was reached by consensus with the addition of a third reviewer. Where required, the corresponding authors were contacted for additional information. Data were extracted from each article included and entered into a Microsoft Excel spreadsheet for analysis. Pertinent information extracted included author, date and journal of publication, study design (and level of evidence), and patient demographics (mean age, mean follow-up, total and group's number of patients, outcome). However, due to heterogeneity of available data in treatment strategy and reporting methods, it was decided to present the review in a narrative manner. Primary studies in the current literature reporting on conservative management of knee OA are characterized by a lot of different treatment protocols and outcomes measures. For this reason, it was not possible to synthesize and systematically analyze the existing data by pooling the results of each study, so as to produce the overall result of a treatment option.

\section{Results}

\section{Literature search}

The literature search yielded 614 potentially relevant records, after duplicates were removed. After screening titles and abstracts, 122 articles were retrieved for full-text evaluation. Eighty-nine studies were excluded for the following reasons: a) studies describing treatments not possible to be performed at home and b) studies including 
pharmacological treatment. Thirty-three studies met the predetermined eligibility criteria and were included in this review. The PRISMA flowchart was applied to illustrate the step-by-step selection process (Fig. 1).

\section{Exercise and physical activity}

Clinical guidelines suggest that exercise is the primary non-pharmacologic treatment of knee OA $[15,16]$. The most common types of exercise used for treating knee OA are low impact aerobic exercise like walking or preferably cycling and resistance training in combination with proprioceptive and range of motion activities [17, 18]. There is sufficient evidence for the favorable effect of exercise on pain reduction and physical function improvement $[19,20]$. As such, patients with knee OA should be encouraged to undertake aerobic, muscle strengthening and range of motion exercises in their daily schedule, while limiting the movements that cause extra pain and axial joint loading [21]. Exercise benefits patients by inducing muscular hypertrophy, strengthening and increasing blood flow and joint lubrication [22].

Three meta-analyses including 60, 48 and 20 randomized controlled trials respectively, demonstrated a beneficial effect of aerobic, resistance and performance exercise on knee OA, but did not recommend the most favorable exercise regimen [23-25]. Very few studies have compared different exercise intensity, duration and progression and, due to different protocols used, the optimal combination still remains uncertain with no type of exercise shown to be better than another [19, 26, 27]. Mixed programmes are recommended when it comes to the type of exercise [15].

Quadriceps strengthening exercises, strength training of the hip or lower limb and aerobic training have favorable effects regarding pain and knee function $[19,28]$. Range of motion exercise prevents development of

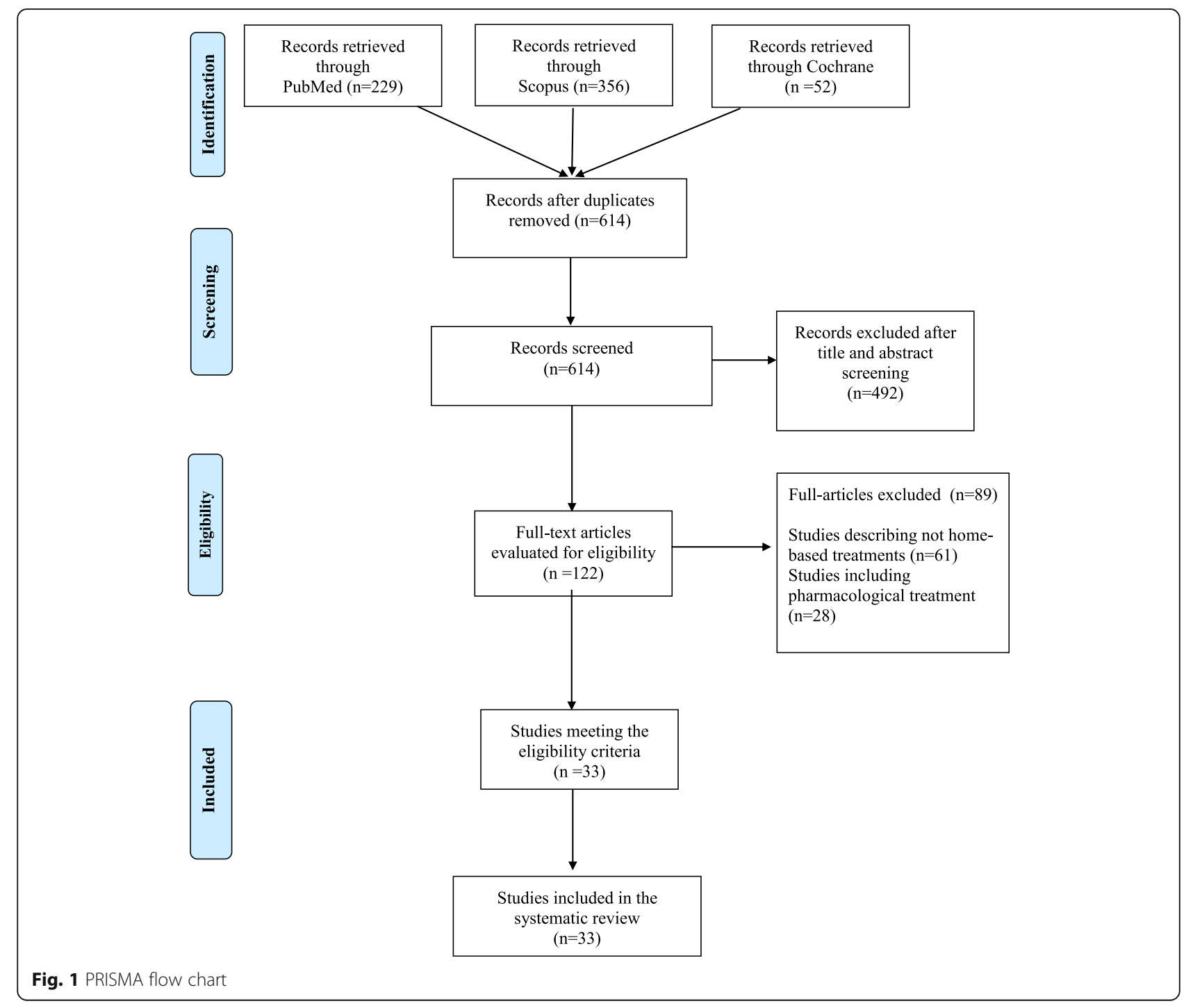


contractures while periarticular muscle strengthening improves symptoms [20, 27]. Stabilization exercises may be used, since OA often leads to instability in the knee due to biomechanical imbalances $[29,30]$. The aforementioned exercises could incorporate progression over time, which has been shown to reduce pain more effectively, when compared with non-progressive programmes $[27,31]$. Running on hard surfaces, jumping, stair climbing and squatting should be limited [32]. The exercise regimen may be adapted according to the pain experienced and functional limitations.

Blood flow restriction (BFR) training is commonly used in athletes to improve hypertrophy in biceps brachii and quadriceps femoris muscles [33]. BFR training uses low resistance exercise and can be effective in improving function and muscle hypertrophy, when conventional quadriceps strengthening programmes with high resistance exercise exacerbate knee symptoms [34]. This concept may contribute to the home-based management of knee OA by ameliorating the quadriceps weakness that often comes with this degenerative condition without provoking training-related knee pain [34]. BFR has been found to be a safe alternative for older adults with knee OA to reduce pain and improve function [35]. A randomized controlled trial from 2018 demonstrated that BFR is able to improve pain, while inducing less knee joint stress in patients with OA compared to resistance training alone [36]. The literature suggests that adherence to physical activity is often directly dependent on the use of exercise plans or log books containing feedback on progress and the effect on pain $[37,38]$.

Most importantly, the clinical status of patients with knee OA during the COVID-19 pandemic, can be improved if patients are contacted regularly by phone or participate in live virtual sessions with their physician or physical therapist [16, 17, 39]. Every exercise programme should be supervised during the first days of implementation at least.

\section{Diet and weight loss}

During the pandemic patients with knee OA mostly stay at home; they should therefore pay special attention to their weight. Weight gain, together with decreased strength of surrounding musculature, may increase the load on the knee [40]. There is evidence that for each kilogram ( $\mathrm{kg}$ ) of weight loss, the knee experiences a $4 \mathrm{~kg}$ reduction in load per step and a $4800 \mathrm{~kg}$ reduction in compressive load for each kilometer walked $[16,41]$. Individualized diet interventions with weight loss goals and involving regular follow up to assess the progress have been associated with pain and functional improvements in overweight patients with severe knee OA [41, 42]. European League Against Rheumatism (EULAR) recommendations on how to control your weight focus on calorie intake, intake of fats and sugar and portion size in combination with self-monitoring and the setting of weight-loss goals [15].

A meta-analysis assessed the changes regarding pain and function in obese patients with knee OA who achieved a weight loss. It demonstrated a significant reduction in disability when weight was reduced $>5.1 \%$ over a 20 -week period or at the rate of $>0.24 \%$ reduction per week [43]. Another study evaluated patients with knee OA and concluded that weight gain $\geq 10 \%$ of body weight was associated with a worse Western Ontario and McMaster Universities Osteoarthritis Index (WOMAC) physical function score [44]. Teichtahl et al. showed that obese patients with OA who lost as little as $1 \%$ of their body weight were able to reduce the amount of medial femorotibial cartilage volume loss [45].

A 18 month RCT demonstrated that the combination of weight loss and exercise is more effective in managing knee OA than either one alone, with patients in the combined diet and exercise group achieving more weight loss and greater reductions in WOMAC pain scores and IL-6 levels [41]. Education on OA management along with information on physical exercises and weight loss by virtual visits to the physician could reinforce the effectiveness of exercise and weight loss programmes when implemented simultaneously [46, 47].

\section{Physical therapy}

A symptomatic patient suffering from severe end-stage knee OA may benefit from referral to a physical therapist for video instructions and supervision [21]. Initial supervised sessions have been shown to act favorably on patient adherence to home exercise programmes, resulting in less pain and improved functioning $[48,49]$.

There is little evidence to support the use of thermal packs or ice packs. However, due to the fact that they are accessible and affordable for most patients, thermal modalities are included in OA treatment guidelines for managing pain [16]. Heat may be applied through warm water or heat packs and could be used at the same time as stretching during painful episodes [16]. Cryotherapy is typically implemented with ice packs for managing acute episodes of inflammation and pain, without any significant effects demonstrated on pain coming from knee OA [21, 50]. Alternation between heat and cold therapies (e.g. starting with a hot pack and ending with a cold one) is often suggested by physical therapists in daily practice; however there is insufficient data in the literature to support potential benefits of this technique [50].

\section{Braces, orthotics and footwear}

Corrective devices, such as knee braces, orthotics and footwear may be effective for management of knee OA symptomatology [40]. Knee bracing and foot orthoses 
may contribute to countering the pain coming from excessive knee adduction moment during walking that has been associated with severe radiographic knee OA [51]. Both of these devices constitute effective means in the home-based armamentarium to tackle pain and joint stiffness [52].

Knee braces are designed to alter contact pressures, especially with uni-compartmental knee OA, by exerting either valgus or varus force [53]. A knee brace can improve stability, reduce the muscular contraction needed to stabilize the affected knee and minimize the risk of falling [21, 54]. Brouwer et al. also demonstrated improved pain scores and walking tolerance at 1 year with knee off-loader braces, especially in the medial compartment OA group [55]. It is suspected that a brace acts by improving the biomechanical axis of the deformity or the perception of instability [32]. Hussain et al. suggested that a patient with uni-compartmental $\mathrm{OA}$ is the ideal one to benefit from an orthosis in terms of pain and function [32]. More high-quality studies are warranted to elucidate which subset of knee OA patients are likely to benefit from knee braces, sleeves and orthotics.

Appropriate footwear is recommended in every patient with knee OA. Shoes could affect by acting as shock absorbers or controlling foot pronation [15, 52]. Turpin et al. demonstrated that the use of shoes with shockabsorbing insoles for 1 month reduced pain and improved functioning [56]. Shoes requirements include shock-absorbing soles, support for the arches, no raised heel and a size big enough to give space for the toes [52]. In patients with medial knee OA, lateral wedge insoles may reduce pain, improve ambulation by reducing knee adduction moment and therefore decrease joint stress; however studies have shown controversial results not always ending in significant benefits $[15,54,57]$.

\section{Walking aids}

Walking aids and assistive technology at home should be considered as a safe alternative in patients with knee $\mathrm{OA}$, since the value of some of these measures has an immediate impact in individual patients [15]. Reduction of pain can be achieved with use of walking aids and patients should be taught the optimal use of a cane or crutch in the contralateral hand, while wheeled walkers are ideal for those suffering from bilateral pathologies $[16,21]$.

Canes are considered affordable means to unload the affected joint, provide stability and potentially reduce pain. Walkers are suggested for patients who require maximum assistance, particularly for the elderly. Patients must have good arm strength bilaterally. However, patients may become dependent on walkers; thus they should typically be prescribed for the pre-operative or early post-operative period or in severe disease circumstances [21]. Finally, it is specified in the literature that walking aids at home play a crucial role in management of knee OA, since $90 \%$ of adult people suffering from severe knee pain report the use of canes [58-60].

\section{Limitations}

The results of the present review should be interpreted in the context of several limitations. First, due to between-study differences in treatment strategy and reporting methods, results could not be pooled. Subsequently, risk of bias of the included studies as well as publication bias of our outcomes could not be assessed. Additionally, the circumstances established by the pandemic led us to find conservative alternatives for the management of knee OA at all stages, and this increases the risk of selection bias for the current review. However, by following the PRISMA guidelines during our search strategy and data extraction, we attempted to provide high-quality evidence-based recommendations for the patients, who have had their knee surgery postponed during COVID-19 pandemic.

\section{Conclusion}

According to this review, under current circumstances established by the pandemic, virtual education on selfmanagement strategies could be part of tackling knee OA. Initiating an exercise programme involving aerobic activity (preferably cycling), strengthening and flexibility is recommended. Obese patients are encouraged to set weight loss goals and adopt healthy nutrition habits. The literature indicates that potential benefits may be gained from the use of knee braces, sleeves, foot orthoses and appropriate footwear but the evidence is weak. Walking aids may be prescribed, when considered necessary, along with the instructions of use. Further research is required to clarify which is the most efficient nonpharmacological, home-based treatment plan for the management of knee OA. Finally, it is crucial to take into consideration that none of these treatments may completely substitute for the life-changing effect of a TKA in patients with severe knee OA. Of course, the ultimate goal is to gradually and safely reinstate elective surgeries with the minimum impact on patients that had their surgery postponed.

\footnotetext{
Abbreviations

AAHKS: American Association of Hip and Knee Surgeons; BFR: Blood flow restriction; COVID-19: Coronavirus disease 2019; EHS: European Hip Society; EKA: European Knee Associates; EULAR: European League Against Rheumatism; kg: Kilogram; OECD: Organization for Economic Co-operation and Development; OA: Osteoarthritis; RCTs: Randomized controlled trials; SARS-CoV-2: Severe acute respiratory syndrome coronavirus 2; TKA: Total knee arthroplasty; WOMAC: Western Ontario and McMaster Universities Osteoarthritis Index
}

Acknowledgements Not applicable. 


\section{Authors' contributions}

TK searched the literature, performed data extraction and wrote the manuscript; $\mathrm{MH}$, NK performed critical revision of the manuscript; IT supervised the manuscript; $\Pi T$ conceptualized the review, searched the literature, performed data extraction and supervised the manuscript; All authors read and approved the final manuscript.

\section{Funding}

This research did not receive any specific grant from funding agencies in the public, commercial, or not-for-profit sectors.

\section{Availability of data and materials}

Data sharing is not applicable to this article as no datasets were analysed during the current study.

\section{Ethics approval and consent to participate}

Not applicable.

\section{Consent for publication}

Not applicable.

\section{Competing interests}

The authors declare that they have no competing interests.

\section{Author details}

${ }^{1}$ School of Medicine, Faculty of Health Sciences, Aristotle University of Thessaloniki, University Campus, 54124 Thessaloniki, Greece. ²Department of Orthopaedic Surgery and Traumatology, Kantonsspital Baselland (Bruderholz, Liestal, Laufen), 4101 Bruderholz, Basel, Switzerland. ${ }^{3}$ CortoClinics, Steeg 6E, 5482 WN Schijndel, The Netherlands. ${ }^{4}$ Thessaloniki Minimally Invasive Surgery Orthopaedic Center, St. Luke's Hospital, 55236 Panorama, Greece.

\section{Received: 1 June 2020 Accepted: 9 July 2020}

\section{Published online: 19 July 2020}

\section{References}

1. Suri P, Morgenroth DC, Hunter DJ (2012) Epidemiology of osteoarthritis and associated comorbidities. PM R 4:S10-S19. https://doi.org/10.1016/j.pmrj. 2012.01.007

2. Carr AJ, Robertsson O, Graves S et al (2012) Knee replacement. Lancet 379 1331-1340. https://doi.org/10.1016/S0140-6736(11)60752-6

3. Ruiz DJ, Koenig L, Dall TM et al (2013) The direct and indirect costs to society of treatment for end-stage knee osteoarthritis. J Bone Joint Surg Am 95:1473-1480. https://doi.org/10.2106/JBJS.L.01488

4. Tsai J, Wilson M (2020) COVID-19: a potential public health problem for homeless populations. Lancet Public Health 5:e186-e187. https://doi.org/10. 1016/S2468-2667(20)30053-0

5. D'Apolito R, Faraldi M, Ottaiano I, Zagra L (2020) Disruption of Arthroplasty practice in an orthopedic Center in Northern Italy during the coronavirus disease 2019 pandemic. J Arthroplast 35(7S):S6-S9. https://doi.org/10.1016/j. arth.2020.04.057

6. Liebensteiner MC, Khosravi I, Hirschmann MT et al (2020) Massive cutback in orthopaedic healthcare services due to the COVID-19 pandemic. Knee Surg Sport Traumatol Arthrosc 28:1705-1711. https://doi.org/10.1007/s00167-02006032-2

7. Xue Y, Kristiansen IS, de Blasio BF (2012) Dynamic modelling of costs and health consequences of school closure during an influenza pandemic. BMC Public Health 12:962. https://doi.org/10.1186/1471-2458-12-962

8. Athey AG, Cao L, Okazaki K et al (2020) Survey of AAHKS international members on the impact of COVID-19 on hip and knee Arthroplasty practices. J Arthroplast. https://doi.org/10.1016/j.arth.2020.04.053

9. Thaler M, Khosravi I, Hirschmann MT et al (2020) Disruption of joint arthroplasty services in Europe during the COVID-19 pandemic: an online survey within the European hip society (EHS) and the European knee associates (EKA). Knee Surg Sport Traumatol Arthrosc 28:1712-1719. https:// doi.org/10.1007/s00167-020-06033-1

10. Chang Liang Z, Wang W, Murphy D, Po Hui JH (2020) Novel coronavirus and Orthopaedic surgery: early experiences from Singapore. JBJS 102:745749. https://doi.org/10.2106/JBJS.20.00236

11. de Caro F, Hirschmann TM, Verdonk P (2020) Returning to orthopaedic business as usual after COVID-19: strategies and options. Knee Surg Sport
Traumatol Arthrosc 28:1699-1704. https://doi.org/10.1007/s00167-02006031-3

12. Mouton C, Hirschmann MT, Ollivier M et al (2020) COVID-19 - ESSKA guidelines and recommendations for resuming elective surgery. J Exp Orthop 7:28. https://doi.org/10.1186/s40634-020-00248-4

13. Hirschmann MT, Hart A, Henckel J et al (2020) COVID-19 coronavirus: recommended personal protective equipment for the orthopaedic and trauma surgeon. Knee Surg Sport Traumatol Arthrosc 28:1690-1698. https:// doi.org/10.1007/s00167-020-06022-4

14. Moher D, Liberati A, Tetzlaff J, Altman DG (2009) Preferred reporting items for systematic reviews and meta-analyses: the PRISMA statement. PLoS Med 6:e1000097. https://doi.org/10.1371/journal.pmed.1000097

15. Fernandes L, Hagen KB, Bijlsma JWJ et al (2013) EULAR recommendations for the non-pharmacological core management of hip and knee osteoarthritis. Ann Rheum Dis 72:1125-1135. https://doi.org/10.1136/ annrheumdis-2012-202745

16. Zhang W, Moskowitz RW, Nuki G et al (2007) OARSI recommendations for the management of hip and knee osteoarthritis, part l: critical appraisal of existing treatment guidelines and systematic review of current research evidence. Osteoarthr Cartil 15:981-1000. https://doi.org/10.1016/j.joca.2007.06.014

17. Chen $H$, Zheng $X$, Huang $H$ et al (2019) The effects of a home-based exercise intervention on elderly patients with knee osteoarthritis: a quasiexperimental study. BMC Musculoskelet Disord 20:160. https://doi.org/10. 1186/s12891-019-2521-4

18. Ojoawo AO, Olaogun MOB, Hassan MA (2016) Comparative effects of proprioceptive and isometric exercises on pain intensity and difficulty in patients with knee osteoarthritis: a randomised control study. Technol Health Care 24:853-863. https://doi.org/10.3233/THC-161234

19. Fransen M, McConnell S, Harmer AR et al (2015) Exercise for osteoarthritis of the knee: a Cochrane systematic review. Br J Sports Med 49:1554-1557. https://doi.org/10.1136/bjsports-2015-095424

20. Jamtvedt G, Dahm KT, Christie A et al (2008) Physical therapy interventions for patients with osteoarthritis of the knee: an overview of systematic reviews. Phys Ther 88:123-136. https://doi.org/10.2522/ptj.20070043

21. Hawkeswood J, Reebye R (2010) Evidence-based guidelines for the nonpharmacological treatment of osteoarthritis of the hip and knee. BCMJ 52:399-403

22. Ferreira RM, Torres RT, Duarte JA, Goncalves RS (2019) Non-pharmacological and non-surgical interventions for knee osteoarthritis: a systematic review and meta-analysis. Acta Reumatol Port Portugal 44:173-217

23. Juhl C, Christensen R, Roos EM et al (2014) Impact of exercise type and dose on pain and disability in knee osteoarthritis: a systematic review and meta-regression analysis of randomized controlled trials. Arthritis Rheumatol 66:622-636. https://doi.org/10.1002/art.38290

24. Uthman OA, van der Windt DA, Jordan $J$ et al (2014) Exercise for lower limb osteoarthritis: systematic review incorporating trial sequential analysis and network meta-analysis. Br J Sports Med 48:1579. https://doi.org/10. 1136/bjsports-2014-5555rep

25. Zampogna B, Papalia R, Papalia GF et al (2020) The role of physical activity as conservative treatment for hip and knee osteoarthritis in older people: a systematic review and meta-analysis. J Clin Med 9:1167. https://doi.org/10. 3390/jcm9041167

26. Jansen MJ, Viechtbauer W, Lenssen AF et al (2011) Strength training alone, exercise therapy alone, and exercise therapy with passive manual mobilisation each reduce pain and disability in people with knee osteoarthritis: a systematic review. J Physiother 57:11-20. https://doi.org/10. 1016/S1836-9553(11)70002-9

27. Pelland L, Brosseau L, Wells G et al (2004) Efficacy of strengthening exercises for osteoarthritis (part I): a meta-analysis. Phys Ther Rev 9:77-108. https:// doi.org/10.1179/108331904225005052

28. Bennell KL, Hunt MA, Wrigley TV et al (2010) Hip strengthening reduces symptoms but not knee load in people with medial knee osteoarthritis and varus malalignment: a randomised controlled trial. Osteoarthr Cartil 18:621628. https://doi.org/10.1016/j.joca.2010.01.010

29. Felson DT, Zhang Y, Anthony JM et al (1992) Weight loss reduces the risk for symptomatic knee osteoarthritis in women. The Framingham study. Ann Intern Med 116:535-539. https://doi.org/10.7326/0003-4819-116-7-535

30. Knoop J, Dekker J, van der Leeden $M$ et al (2013) Knee joint stabilization therapy in patients with osteoarthritis of the knee: a randomized, controlled trial. Osteoarthr Cartil 21:1025-1034. https://doi. org/10.1016/j.joca.2013.05.012 
31. Lange AK, Vanwanseele B, Fiatarone Singh MA (2008) Strength training for treatment of osteoarthritis of the knee: a systematic review. Arthritis Rheum 59:1488-1494. https://doi.org/10.1002/art.24118

32. Hussain SM, Neilly DW, Baliga S et al (2016) Knee osteoarthritis: a review of management options. Scott Med J 61:7-16. https://doi.org/10.1177/ 0036933015619588

33. Hansen SK, Ratzer J, Nielsen JL et al (2020) Effects of alternating blood-flow restricted training and heavy-load resistance training on myofiber morphology and mechanical muscle function. J Appl Physiol 128:15231532. https://doi.org/10.1152/japplphysiol.00015.2020

34. Van Cant J, Dawe-Coz A, Aoun E, Esculier J-F (2020) Quadriceps strengthening with blood flow restriction for the rehabilitation of patients with knee conditions: a systematic review with meta-analysis. J Back Musculoskelet Rehabil:1-16. https://doi.org/10.3233/bmr-191684

35. Cook SB, LaRoche DP, Villa MR et al (2017) Blood flow restricted resistance training in older adults at risk of mobility limitations. Exp Gerontol 99:138145. https://doi.org/10.1016/j.exger.2017.10.004

36. Ferraz RB, Gualano B, Rodrigues R et al (2018) Benefits of resistance training with blood flow restriction in knee osteoarthritis. Med Sci Sports Exerc 50: 897-905. https://doi.org/10.1249/MSS.0000000000001530

37. Murphy SL, Lyden AK, Smith DM et al (2010) Effects of a tailored activity pacing intervention on pain and fatigue for adults with osteoarthritis. Am J Occup Ther 64:869-876. https://doi.org/10.5014/ajot.2010.09198

38. Pisters MF, Veenhof C, de Bakker DH et al (2010) Behavioural graded activity results in better exercise adherence and more physical activity than usual care in people with osteoarthritis: a cluster-randomised trial. J Physiother 56: 41-47. https://doi.org/10.1016/s1836-9553(10)70053-9

39. Rene J, Weinberger M, Mazzuca SA et al (1992) Reduction of joint pain in patients with knee osteoarthritis who have received monthly telephone calls from lay personnel and whose medical treatment regimens have remained stable. Arthritis Rheum 35:511-515. https://doi.org/10.1002/art. 1780350504

40. Fibel KH, Hillstrom HJ, Halpern BC (2015) State-of-the-art management of knee osteoarthritis. World J Clin Cases 3:89-101. https://doi.org/10.12998/ wjcc.v3.i2.89

41. Messier SP, Mihalko SL, Legault C et al (2013) Effects of intensive diet and exercise on knee joint loads, inflammation, and clinical outcomes among overweight and obese adults with knee osteoarthritis: the IDEA randomized clinical trial. JAMA 310:1263-1273. https://doi.org/10.1001/jama.2013.277669

42. Foy CG, Lewis CE, Hairston KG et al (2011) Intensive lifestyle intervention improves physical function among obese adults with knee pain: findings from the look AHEAD trial. Obesity (Silver Spring) 19:83-93. https://doi.org/ 10.1038/oby.2010.120

43. Christensen R, Bartels EM, Astrup A, Bliddal H (2007) Effect of weight reduction in obese patients diagnosed with knee osteoarthritis: a systematic review and meta-analysis. Ann Rheum Dis 66:433-439. https://doi.org/10. 1136/ard.2006.065904

44. Riddle DL, Stratford PW (2013) Body weight changes and corresponding changes in pain and function in persons with symptomatic knee osteoarthritis: a cohort study. Arthritis Care Res (Hoboken) 65:15-22. https:// doi.org/10.1002/acr.21692

45. Teichtahl AJ, Wluka AE, Tanamas SK et al (2015) Weight change and change in tibial cartilage volume and symptoms in obese adults. Ann Rheum Dis 74:1024-1029. https://doi.org/10.1136/annrheumdis-2013-204488

46. Hurley MV, Walsh NE, Mitchell H et al (2012) Long-term outcomes and costs of an integrated rehabilitation program for chronic knee pain: a pragmatic, cluster randomized, controlled trial. Arthritis Care Res (Hoboken) 64:238-247. https://doi.org/10.1002/acr.20642

47. Ravaud P, Flipo R-M, Boutron I et al (2009) ARTIST (osteoarthritis intervention standardized) study of standardised consultation versus usual care for patients with osteoarthritis of the knee in primary care in France: pragmatic randomised controlled trial. BMJ 338:b421. https://doi.org/10. 1136/bmj.b421

48. Ettinger WHJ, Burns R, Messier SP et al (1997) A randomized trial comparing aerobic exercise and resistance exercise with a health education program in older adults with knee osteoarthritis. The fitness arthritis and seniors trial (FAST). JAMA 277:25-31

49. McCarthy CJ, Mills PM, Pullen R et al (2004) Supplementing a home exercise programme with a class-based exercise programme is more effective than home exercise alone in the treatment of knee osteoarthritis. Rheumatology (Oxford) 43:880-886. https://doi.org/10.1093/rheumatology/keh188
50. Brosseau L, Yonge KA, Robinson V et al (2003) Thermotherapy for treatment of osteoarthritis. Cochrane Database Syst Rev 4:CD004522. https://doi.org/ 10.1002/14651858.CD004522

51. Sharma L, Hurwitz DE, Thonar EJ et al (1998) Knee adduction moment, serum hyaluronan level, and disease severity in medial tibiofemoral osteoarthritis. Arthritis Rheum 41:1233-1240. https://doi.org/10.1002/15290131(199807)41:7<1233:.AID-ART14>3.0.CO;2-L

52. Raja K, Dewan N (2011) Efficacy of knee braces and foot orthoses in conservative management of knee osteoarthritis: a systematic review. Am J Phys Med Rehabil 90:247-262. https://doi.org/10.1097/PHM. Ob013e318206386b

53. Kirkley A, Webster-Bogaert S, Litchfield R et al (1999) The effect of bracing on varus gonarthrosis. J Bone Joint Surg Am 81:539-548. https://doi.org/10. 2106/00004623-199904000-00012

54. Bennell KL, Bowles K-A, Payne C et al (2011) Lateral wedge insoles for medial knee osteoarthritis: 12 month randomised controlled trial. BMJ 342: d2912. https://doi.org/10.1136/bmj.d2912

55. Brouwer RW, Jakma TSC, Verhagen AP et al (2005) Braces and orthoses for treating osteoarthritis of the knee. Cochrane Database Syst Rev 1:CD004020. https://doi.org/10.1002/14651858.CD004020.pub2

56. Turpin KM, De Vincenzo A, Apps AM et al (2012) Biomechanical and clinical outcomes with shock-absorbing insoles in patients with knee osteoarthritis: immediate effects and changes after 1 month of wear. Arch Phys Med Rehabil 93:503-508. https://doi.org/10.1016/j.apmr.2011.09.019

57. van Raaij TM, Reijman M, Brouwer RW et al (2010) Medial knee osteoarthritis treated by insoles or braces: a randomized trial. Clin Orthop Relat Res 468: 1926-1932. https://doi.org/10.1007/s1 1999-010-1274-z

58. Jinks C, Ong BN, Richardson J (2007) A mixed methods study to investigate needs assessment for knee pain and disability: population and individual perspectives. BMC Musculoskelet Disord 8:59. https://doi.org/10.1186/14712474-8-59

59. Jones A, Silva PG, Silva AC et al (2012) Impact of cane use on pain, function, general health and energy expenditure during gait in patients with knee osteoarthritis: a randomised controlled trial. Ann Rheum Dis 71:172-179. https://doi.org/10.1136/ard.2010.140178

60. Mann WC, Hurren D, Tomita M (1995) Assistive devices used by homebased elderly persons with arthritis. Am J Occup Ther 49:810-820. https:// doi.org/10.5014/ajot.49.8.810

\section{Publisher's Note}

Springer Nature remains neutral with regard to jurisdictional claims in published maps and institutional affiliations.

\section{Submit your manuscript to a SpringerOpen ${ }^{\circ}$ journal and benefit from:}

- Convenient online submission

- Rigorous peer review

- Open access: articles freely available online

High visibility within the field

- Retaining the copyright to your article

Submit your next manuscript at $\boldsymbol{\nabla}$ springeropen.com 